\title{
Research on Constructing the Platform of Teaching Resources to Promote the Informatization of Higher Education
}

\author{
QU Qinghong ${ }^{\mathrm{a}}$, JIANG Chunxu ${ }^{\mathrm{b}}$, GAO Feng ${ }^{\mathrm{c}}$ \\ Baicheng Normal University, Baicheng 137000, China \\ aemail: quqinghong@163.com, bemail: 115721119@qq.com, cemail: gaof317@163.com
}

\section{Keywords: Teaching Resource Platform, Campus Informationization, Study}

\begin{abstract}
In recent years, the level of informatization in our country has developed to a certain extent, and has been widely used in the specific education and teaching work. The construction of modern education platform is the core part of the education information work. It is also of great significance to the educational effect of information technology in colleges and universities in China. This paper mainly probes into the construction of information platform for teaching resources.
\end{abstract}

\section{Introduction}

In recent years, the informationization of higher education in our country has been developed to a certain extent, and has been continuously developed towards the direction of digitalization, multimedia and networking. In order to ensure the quality of higher education, colleges and universities are required to actively construct the platform of teaching resources, so that they can fully meet the needs of information resources in the teaching process of colleges and universities. To achieve the sharing of teaching resources, so as to cultivate a group of high-quality innovative application talents.

\section{The Internal Meaning of Teaching Information Resources}

With the arrival of the information age, the process of university education informatization has also been deeply developed, and began to develop towards the direction of digitization, multimedia and networking. Under this background. This has led to a series of major changes and influences in the mode, methods and management measures of higher education. In addition, in the process of training high-quality innovative talents. There will also be a large number of teaching information resources in the whole university education system, that is, the network teaching resources that people often say. Only to realize the sharing of network teaching resources in colleges and universities. In order to maximize the value of these resources. At present, the construction of teaching resources platform in colleges and universities is mainly divided into two parts: the construction of resource platform and the construction of high-quality teaching resources. Only through the collection and sharing of these two resources can we provide enough teaching resources for the actual teaching of colleges and universities, and promote the further development of higher education in our country[1].

\section{Some Problems in the Construction of Educational Resources in Colleges and Universities at Present}

Insufficient Attention to Resource Construction. In the process of constructing teaching resources platform, most colleges and universities also take a series of measures, but in the specific construction process. Some colleges and universities directly put resources and energy on the purchase of a variety of multimedia equipment, but do not pay attention to the later use of these equipment efficiency and resource carrying situation. For the collection of various teaching resources and the construction of resource management team are mostly ignored attitude. In this construction mode[2]. As a result, the campus network and many instruments in colleges and 
universities are unable to give full play to their own effectiveness, which has caused a certain degree of hindrance to the work of higher education in China. Therefore, only the status of equipment and network can be clearly recognized. And the absorption and sharing of resources as an important part of the construction of the whole teaching resources platform can realize the effective sharing of various teaching resources. In order to promote the further development of the education industry in our country, it is necessary to take the development and setting up of the soft resources as the core content in the process of carrying out the education information work.

The Utilization Rate is too Low. In the construction process of network teaching resources, it is not only the traditional teaching resources digital and network processing. It is also necessary to re-plan the course content on the basis of the analysis of the market changes of the subject and the characteristics of network teaching. Design and construction work. But at this stage, some colleges and universities are strengthening the construction of digital campus and network teaching resources database. But the concrete construction content only contains a simple FTP resource bank or a series of test questions and courseware, and the construction of teaching resources in colleges and universities as part of the simple accumulation of teaching content. Its resources content is simple, the classification is too general, teachers or students in the process of seeking resources often need a lot of time and energy, but also difficult to retrieve the content they want. In addition, some colleges and universities even take the construction of teaching resources as the purchase of a large number of teaching CDs and tapes. As long as these resources are copied and stored, it is considered that the construction of teaching resources has been done well, which leads to a serious lack of utilization and application enthusiasm of each teaching resource[3].

Teaching Resources Construction is too Simple. At this stage, many colleges and universities have strengthened the construction of teaching resources platform, but in the process of storage and management of teaching resources, the traditional management model is still applied. In addition, some colleges and universities have a corresponding management platform, but in the daily management process, there are still some slow update speed and poor interaction. Resource content is too messy and the use of many other problems, for network security awareness is also seriously inadequate, which also led to the lack of teachers and students in colleges and universities to the application of resources pool enthusiasm. Therefore, it is difficult to give full play to the value of teaching resources themselves.

The Standardization of Teaching Resources is Insufficient. For colleges and universities, the nature of the construction of teaching resources is a process of continuous accumulation, and need to involve more than one unit of teaching resources. In this form. It is easy to lead to the lack of uniform standards and rules of teaching resources in colleges and universities, and there are also great differences in the format division and naming process of resources. There are also some problems, such as overlapping, which is not only unfavorable to the use of teachers and students, but also to the smooth development of the management of these teaching resources.

Lack of Incentives and Safeguards. In the process of constructing teaching resource platform, colleges and universities lack of unified coordination. It leads to many colleges and universities are their own development and their own acquisition and construction, and in the teaching resources have not played a good sharing effect. And lead to a large number of human and financial resources are wasted. In addition, in the specific construction of teaching resources platform, because of the lack of incentives and safeguards, it also leads to the lack of enthusiasm for the production of high-quality teaching resources. The intellectual property rights of some high quality resources have not taken effective protection measures, which has directly affected the construction of the teaching resources platform in colleges and universities[4].

\section{Design Requirements and Functions of Information Resources Platform in China}

Design Requirements. The purpose of constructing teaching resource platform in colleges and universities is to strengthen their talents training ability and realize the predetermined talent training target. Therefore, in the process of constructing teaching resources platform. It is necessary for colleges and universities to collect and measure the teaching information produced and released in 
the course of teaching through a variety of management means on the basis of combining the educational law and the management law. Through the scientific processing and control of these resources to provide sufficient resources for the corresponding teaching work. Through the construction of teaching resources management platform, more educational resources can be effectively shared. Therefore, it is convenient for users to communicate and manage, so that students' learning enthusiasm and initiative can be effectively promoted, so in the process of constructing and designing the educational platform. Need to fully meet the following points of actual demand.

The improvement of hardware equipment, smooth and stability: under the support of campus network, the university should be able to further strengthen the construction of hardware equipment. The concrete construction contents include the configuration of resource file server and database server with excellent nature, in addition, the construction of recording and playing system and corresponding technicians should be strengthened. Only in this way can we fully guarantee the unblocked network and the security and stability of various hardware devices, and form a good teaching resource information center.

In the process of classification of data resources, we need to maintain good standardization: in the process of constructing teaching resources platform, we can classify all kinds of educational resources effectively. It will also directly determine the performance of the system, a good resource classification effect can make the data structure of the system more clean. And further improve the speed of data retrieval and use of users. But at this stage of the teaching resources platform construction process, for the category. The classification of multimedia teaching resources in many formats is still lack of corresponding standards and norms as a reference. Therefore, it is necessary to combine the national standard subject code list on the basis of. After completing the task of classifying the teaching resources, we can subdivide them according to the attributes of the resources themselves.

The completeness of system resources and the friendliness of interface: in the process of designing system resources. Require it to meet the following needs: first: easy to use and maintenance management: students can quickly find what they want to learn, and through the system to effectively communicate with students. In order to play a good learning feedback effect. Second: has a higher application efficiency: in the process of system design. All functions are required to take performance and efficiency as the important basis. Third: the expansion of function: the teaching resources in colleges and universities are in the process of continuous expansion and change. Therefore, the system also needs to have a good later extension function, so that in the process of use if found some more high-quality application functions or deficiencies. On the basis of not changing the original data directly, it can play a good function expansion effect, so that the applicability of the educational resources system in colleges and universities has been greatly improved.

The security of the system in teaching resources system in Colleges and universities have a very large amount of data, and various resources of intellectual property has some differences, which also need to protect the security of the system. In the system security work, the first step is to ensure the teaching resources, teachers and students' information safety, followed by the need to avoid occurring during the use of the system in the data is lost or can not be used in the system. So the design process, a series of safety problems also requires the design of relevant personnel can meet on the hardware design and the software development process, so as to ensure the application of the performance of the whole system[5].

System Module. Client use module: this module can use browser to quickly view, order and download the various teaching resources in the system. It can be combined with the search conditions of users to quickly search the relevant resources in the database. Then the fuzzy query model is applied to quickly find all kinds of resources that users need. In addition, in the client module, teachers and students need to communicate with each other, and need to have the function of contact. Recording learning notes and adding learning labels gives users enough convenience to use them. 
Administrator module: in the teaching resource platform system, different levels of administrators have some differences in their permissions. In addition, the administrator needs to manage the information of teachers and students effectively. In addition, teachers can also make use of the corresponding teacher modules to upload their own online courses and learning questions bank, and can deal with the problems of students in time. To realize the interaction and communication with the students.

The retrieval module of system retrieval accuracy and speed will directly affect the application effect of the teaching resources platform, so in the process of retrieval module system design requirements, which can timely all the hot words, and be able to edit the data dictionary of keywords retrieval module. In addition to the need for accurate preparation of keywords according to the data resources, and then the keyword entry to the backstage database dictionary, to facilitate the users of the system can quickly find their desired content.

Interface template: with the help of individual interface design and the application of CSS technology, users can get a richer style, in addition, through a powerful functional interface, but also for the continuous expansion of new features. So that the system can be continuously updated to give users a good system application experience.

\section{Some Suggestions on the Construction of Teaching Resources platform}

With the continuous development of information technology, colleges and universities in their own teaching process also began to be widely used in information technology and multimedia technology, in this teaching background. Teaching resources show explosive growth. In order to maximize the advantages of the application of these resources, colleges and universities are required to actively build a platform for the management of teaching resources. Only in this way can we deal with the various teaching resources effectively and promote the further development of the education industry in our country. And in the process of constructing the teaching resources platform. We also need to pay full attention to the following points.

Strengthen the Attention of School Leaders. School leaders need to pay enough attention to modern educational technology and the construction of educational informatization in colleges and universities, and need to be guided by the concept of educational informatization development. To strengthen the construction of teaching resources platform investment, and to provide a good digital environment. On the basis of a reasonable formulation of policies and incentives. Colleges and universities are also required to build specialized management and technical service centers. Only in this way can we lay a good foundation for the construction of teaching resources platform.

Strengthen the Participation of Teachers. In the process of constructing teaching resource platform, all teachers are actively involved in it. In order to improve the quantity and quality of teaching resources effectively, colleges and universities need to take appropriate incentives, and need to launch a series of educational information competition activities. To enable teachers to actively participate in the construction of teaching resources platform, and constantly improve their teaching level. In addition, teachers also need to continue to improve their teaching concepts. To actively participate in the research and development of quality courses and network courses.

Construct a Perfect Safeguard System. In the process of constructing the teaching resource platform, the intellectual property problem can not be solved effectively, which leads to the reluctance of some teachers to participate in the construction of teaching resources database. In order to avoid the misappropriation of resources carefully prepared by teachers, colleges and universities can also use IP restrictions and watermark coverage mode. To help teachers solve the problem of intellectual property rights. Only by building a sound intellectual property protection system and solving the problem of intellectual property theft can teachers' worries be effectively solved. To make the quality of teaching resources to a certain extent.

\section{Conclusion}

The construction of teaching resources management platform is a long-term project, an important 
basis for the informatization construction of the colleges and universities. Therefore universities also need to strengthen the work of attention, and through the diversified teaching mode, the teaching resources in Colleges and universities across the country to get optimal allocation, so as to promote the further development of our in the process of educational informatization.

\section{Acknowledgement}

In this paper, the research was sponsored by the Educational Science Project of Jilin province during “13th Five-Year Plan” in 2017 (No. GH170595) .

\section{References}

[1] LIU Yuchun. Research on problems and Countermeasures of Network Teaching in Colleges and Universities[J]. Journal of Inner Mongolia Normal University (Educational Science), 2017, (10): 132-135.

[2] WANG Yuqing, WU Guoying. Research on the Integration of Network Teaching Platform and Library Literature Resources in Colleges and Universities[J].Shanxi Archives,2015,(1):75-77.

[3] LI Juan, MING Deting. Discussion on the sharing of Educational Resources in Colleges and Universities[J].Value Engineering,2018,(1):167-168.

[4] ZHANG Yang. Research on the Construction of Teaching Resources of Cloud Education platform in Colleges and Universities[J].Science and Technology Innovation Herald, 2017, (13): 213-214.

[5] ZHANG Shouli. Research on the sharing platform of Teaching Resources in Colleges and Universities[J]. China Computer \& Communication,2017,(21):236-237,240. 